\title{
El experimento uruguayo: Actores políticos y sociales en el proceso de regulación del cannabis
}

The Uruguayan experiment: Political and social actors in the process of cannabis regulation

\author{
Alicia Lissidini \\ Profesora Titular de la Escuela de \\ Política y Gobierno, Universidad \\ Nacional de San Martín e investigadora \\ asociada del CIESU \\ (Centro de Información y Estudios \\ del Uruguay); \\ alicia.lissidini@gmail.com \\ Inés Pousadela \\ Especialista Senior de Investigación \\ de CIVICUS: Alianza Mundial para la \\ Participación Ciudadana y profesora \\ de la Universidad ORT Uruguay; \\ pousadel@gmail.com
}

\section{Resumen}

En diciembre de 2013 Uruguay se convirtió en el primer país del mundo en regular el cultivo, la posesión, venta y consumo de cannabis en todo su territorio, y en colocar al Estado en el centro del sistema de producción de la sustancia destinada al mercado. Este estudio de caso busca dar cuenta de esta singular innovación en materia de política pública mediante el análisis de roles, estrategias e interacciones entre actores sociales y políticos. Nuestra explicación subraya el rol del liderazgo presidencial; la importancia del contexto partidario e institucional uruguayo, y particularmente del dispositivo de la disciplina partidaria; y el rol de una demanda preexistente, movilizada y presente tanto en la sociedad civil como dentro del sistema político.

Palabras clave: Uruguay - cannabis - liderazgo presidencial - partidos políticos - movimientos sociales

\section{Abstract}

In December 2013, Uruguay became the first country in the world to regulate the cultivation, possession, sale and consumption of cannabis throughout its territory, and to put the State at the center of the production system of cannabis destined to the market. This case study seeks to account for this unique innovation in public policy through
15.2.18

Fecha de recepción:

12.12.17

Fecha de aceptación: 
the analysis of roles, strategies and interactions between social and political actors. Our explanation underscores the role of presidential leadership; the importance of the Uruguayan partisan and institutional context, and of party discipline in particular; and the role of a preexisting demand, mobilized and present both in civil society and within the political system.

Keywords: Uruguay - cannabis - presidential leadership - political parties - social movements

Yo estoy convencido del consejo de Einstein: cuando tú quieres cambiar las cosas y vuelves a hacer lo mismo, no cambia nada. Entonces hace tantos años que reprimimos y perseguimos y cada vez estamos peor, que empezamos a pensar otras alternativas. [...] La vida es un experimento. Solamente los dogmáticos, los sectarios, los que se niegan a cualquier cambio, pueden estar en contra de la honradez de la palabra experimento. Vivir es experimentar, buscar soluciones que a veces sirven $y$ a veces no. ¿Por qué resulta que ahora reconocemos el matrimonio igualitario $y$ antes no? ¿Cuándo experimentamos: ayer u hoy? ¿Por qué cambiamos? ¿Y la esclavitud cómo se fue del mundo? Toda la vida ha sido eso. Ahora, los remachados retrógrados que no quieren cambios para nada, seguro se van a asustar. Yo reivindico la palabra experimento.

José Mujica (BBC, 7/05/14)

\section{Introducción ${ }^{1}$}

Con la aprobación, en diciembre de 2013, de la ley 19.172, Uruguay se convirtió en el primer país del mundo en regular el cultivo, la posesión, la venta y el consumo de cannabis en todo su territorio, además de poner al Estado en el centro del sistema de producción de la sustancia destinada al mercado. ${ }^{2}$ Contrariamente a lo que se suele creer, la nueva legislación no legalizó el consumo de marihuana, pues éste ya era legal desde mucho tiempo atrás. Lo que hizo fue eliminar las contradicciones -hipocresías, según los promotores de la nueva ley- de la vieja legislación, que toleraba el consumo pero prohibía todas las vías para obtener el producto, forzando al usuario a incurrir en 
conductas ilegales. Lo hizo mediante la introducción de una serie de regulaciones que se aplican en cada eslabón de la cadena, desde la investigación hasta el consumo, pasando por el cultivo, la comercialización, el almacenamiento y la distribución. Un nuevo organismo, el Instituto de Regulación y Control del Cannabis (IRCCA), fue puesto a cargo de la emisión de licencias, el mantenimiento de registros y la regulación y el control de todas las actividades de importación, producción, adquisición a cualquier título, almacenamiento, comercialización y distribución de la marihuana y sus derivados.

La ley 19.172 dispone que los ciudadanos uruguayos o residentes mayores de edad podrán, previo registro, adquirir hasta 10 gramos de cannabis por semana (y hasta un máximo de 40 gramos por mes) en farmacias autorizadas. En respuesta a una demanda de larga data de numerosas organizaciones sociales, la ley también habilita el llamado "autocultivo" tanto individual (con un máximo de seis plantas hembra en floración, hasta 440 gramos anuales) como colectivo. Para este último propósito se habilitaron los clubes de cannabis, que según la ley deben formarse como entidades sin fines de lucro con entre 15 y 45 socios y hasta 99 plantas. Es gracias a estas dos opciones que -destaca una joven activista pro-liberación- "ahora podemos ejercer nuestro derecho sin alimentar el narcotráfico" y sin "envenenarnos con la porquería tóxica que traen de Paraguay". ${ }^{3}$

En las páginas que siguen presentamos un estudio de caso guiado por el objetivo de dar cuenta de esta singular innovación en materia de política pública, analizando especialmente el cómo de su aprobación. Realizamos, en consecuencia, un análisis cualitativo y de trazado de procesos, de modo de rastrear la propuesta desde sus inicios hasta su conversión en ley, colocándola en contexto y atendiendo a las interacciones, motivaciones, acciones (y consecuencias no intencionadas de las acciones) de los principales actores. Esta investigación se basa en fuentes secundarias y entrevistas con algunos actores clave. En primer lugar, se realizó un rastreo de medios centrado en tres periódicos de orientaciones ideológicas marcadamente diferentes: El Observador, El País y La Diaria. De ese modo se reconstruyó el proceso desde que el tema de la regulación del cannabis comenzó a circular en el debate público hasta que fue aprobada la ley; adicionalmente se hizo luego un seguimiento, menos intenso, del prolongado proceso de implementación de la nueva ley. El relevamiento de prensa también abarcó a los análisis de fondo publicados regularmente en dos semanarios - Brecha y Búsqueda - que dieron espacio, respectivamente, a las voces políticas y sociales a favor y en contra de la regulación. En el curso del proceso se incorporaron al análisis los resultados de investigaciones realizadas por otros colegas así como, llegado el momento, las transcripciones de las sesiones parlamentarias. Finalmente, las autoras entrevistaron a algunos actores clave y, en el curso de sucesivas ediciones del encuentro anual ExpoCannabis, mantuvieron conversaciones informales con activistas y expertos. 
Este trabajo se enmarca en un proyecto de investigación más amplio sobre los movimientos sociales contemporáneos en Uruguay, guiado por un interrogante más general sobre la relación entre partidos políticos, sociedad civil y Estado. En ese marco viene a sumarse a otros estudios realizados por las autoras, entre ellos sobre el movimiento de mujeres y su labor conducente a la aprobación de la Ley de Interrupción Voluntaria del Embarazo a fines de 2012 (Pousadela 2016) y sobre la ampliación de la agenda de derechos en Uruguay (Lissidini 2016).

\section{Sobre experimentos e innovaciones politicas}

Desde el título en adelante, hemos optado por definir a la política uruguaya de regulación del cannabis como un experimento sociopolítico. Esa fue de hecho la caracterización del proceso provista y defendida públicamente por su singular portavoz global, el entonces presidente José Mujica.

En el terreno sociopolítico, así como en el económico, la noción de experimento no tiene buena prensa; se la encuentra por lo general (y, en el terreno de las políticas económicas, con cierta justicia) asociada a ideas de peligro e irresponsabilidad. A diferencia de lo que ocurre en un laboratorio, esta clase de "experimentos" tiene lugar en condiciones dificiles de controlar y los afectados por la manipulación de las variables tienen una capacidad extremadamente limitada, si es que alguna, para dar su consentimiento informado. Los efectos de una decisión desafortunada pueden ser mucho más vastos que los imaginados por los responsables de la decisión, y revertirlos puede resultar extremadamente dificil, cuando no imposible. No resulta sorprendente, por lo tanto, que desde su primera formulación pública, la caracterización de la regulación del cannabis como "experimento" se convirtiera en foco de interminables controversias. Aún cuando "experimento" fuera el provocador nombre de Mujica para la innovación política, y los riesgos de esta innovación específica no fueran muy diferentes en su naturaleza y sus alcances de los que lleva aparejados toda innovación significativa en el terreno de las políticas públicas.

En diciembre 2013, en entrevista con Folha de São Paulo, Mujica extendió al mundo el pedido de "que nos ayude a hacer esta experiencia, que nos permita adoptar un experimento sociopolítico delante de un problema grave como es el narcotráfico. El efecto del narcotráfico es peor que el de la droga" (FSP, 2/12/13). La respuesta estuvo a cargo del senador del Partido Colorado Pedro Bordaberry, quien sostuvo que el uso de la palabra "experimento" implicaba que "no estás seguro del resultado de lo que vas a hacer", y destacó la inmoralidad de "experimentar con los niños y los muchachos uruguayos" (MP, 9/12/13). En efecto, el reconocimiento de la posibilidad de error formaba parte integral de la visión del experimento que manejaba el entonces presidente, quien justamente proponía el experimento como una tarea de prueba y error a la que solo cabía someterse si se estaba dispuesto a enderezar las acciones en función de los resultados. Así, partiendo de la base de que todas las políticas contra el narcotráfico intentadas hasta la fecha habían 
fracasado, y de que las condiciones uruguayas se prestaban al rol de laboratorio para experimentar con algo nuevo, el presidente admitía que "si algo logramos será a favor de la humanidad, y si nos equivocamos tendremos el coraje político de decir: ¡Nos equivocamos! Pero hay que salir del miedo de no cambiar de camino" (TS, 5/03/14).

El ofrecimiento de "experimentar a favor del mundo sin ofender a nadie" fue precisamente una de las razones por las cuales a principios de 2014 un centenar de profesores universitarios alemanes solicitó la postulación de Mujica para el Premio Nobel de la Paz. Para los catedráticos, se trataba de una "insólita, pero valiente y enérgica estrategia que es probable que constituya un nuevo paradigma en la política de seguridad y salud pública” (EO, 29/01/14). Poco después, "el revolucionario que legalizó la hierba" fue celebrado por la revista Time como una de las cien personalidades más influyentes del año (Time, 23/04/14).

La apuesta, aptamente descripta por su principal portavoz institucional como un experimento de final abierto, constituye según nuestro análisis el resultado de las interacciones entre -y sobre todo, de la peculiar convergencia de- una pluralidad de actores sociales, político-partidarios e institucionales. Una convergencia que, como veremos, se produjo cuando la demanda de un actor (el movimiento pro-legalización, abanderado de un derecho individual) fue recogida por otro actor, en este caso el presidente en funciones, que la interpretó como una posible solución a problemas muy diferentes de los que movían a aquél: el narcotráfico y la criminalidad a él asociada, en primer lugar;y el aumento alarmante de la cantidad de adictos a drogas mucho más dañinas ingresadas por el narcotráfico, en segundo lugar. Así, ante el fracaso de la "guerra contra las drogas" y en un contexto signado por reclamos sociales por la inseguridad, el líder del Ejecutivo impulsó como propia una iniciativa de regulación que el movimiento de consumidores y autocultivadores de cannabis sabía desde un principio más apta para solucionar su propio problema (el de las contradicciones de la legislación existente y su aplicación restrictiva de los derechos individuales) que para enfrentar el problema de política pública que desvelaba al presidente.

En suma, partimos de la hipótesis de que la ley 19.172 fue el producto de la combinación de la movilización social a favor de la reglamentación del cannabis, y especialmente del autocultivo, un sistema de partidos todavía "enraizado" (Lissidini 2016; Pousadela 2017) y compuesto de partidos inusualmente disciplinados, y un gobierno que decidió enfrentar con lo que entendió era una dosis de creatividad política la lucha contra el narcotráfico y la inseguridad. Así, en el camino hacia la regulación coexistieron, no siempre cómodamente, reivindicaciones de derechos individuales a los que se buscaba poner a resguardo de la intervención represiva del Estado y consideraciones vinculadas con la lucha contra la inseguridad y el narcotráfico. A ellas vinieron a sumarse también consideraciones médicas y de salud pública. Como se destaca en la sección dedicada al rol del saber experto, los argumentos vinculados con la salud fueron motorizados, por 
un lado, por entidades tanto públicas como de la sociedad civil ocupadas en la lucha contra las adicciones; por el otro, por grupos de investigación médica y organizaciones de la sociedad civil constituidas en torno de la busca de paliativos y curas para determinadas enfermedades, cuyas esperanzas estaban colocadas en la investigación y la explotación de las propiedades medicinales del cannabis.

Aunque por diversos motivos la implementación de la nueva ley sufrió varios retrasos, desde el 19 de julio de 2017 la marihuana de producción estatal para uso recreativo se consigue en farmacias uruguayas a un precio que actualmente ronda los 7 dólares por 5 gramos. ${ }^{5}$ Para poder comprar, los usuarios deben registrarse, y solo pueden hacerlo si cuentan con un documento uruguayo. Hasta la fecha hay 21.076 personas registradas. Adicionalmente, existen 78 clubes de cannabis ${ }^{6}$ y 8.092 cultivadores individuales inscriptos en el IRCCA (EO, 30/01/18). Por su parte, en octubre 2017 el presidente Tabaré Vázquez firmó un decreto para habilitar a las farmacias a vender productos medicinales elaborados en base a cannabis, con las mismas exigencias que se aplican a cualquier receta médica (EP, 19/10/17). De esta manera pasó a responder a una demanda social que la ley en principio no había atendido. Desde diciembre 2017 estos productos medicinales se venden en las farmacias uruguayas, al igual que en las de algunos otros países de la región. Sin embargo, la situación del Uruguay sigue siendo única tanto por la dimensión nacional de su legislación como por el hecho de que ésta abarca tanto al cannabis medicinal como al recreativo. De ahí que el país siga constituyendo un caso de laboratorio para analizar el impacto en el mediano y el largo plazos de la reglamentación y venta de drogas por parte del Estado.

En las páginas que siguen buscamos explicar cómo y porqué, pese a su apoyo minoritario en la opinión pública local y el rechazo rotundo de los centros de poder internacionales, este "experimento sociopolítico" pasó con éxito por el Parlamento y, más de tres años más tarde, logró alcanzar la fase de venta de marihuana en farmacias. Para ello comenzamos por caracterizar el panorama político institucional, y más precisamente el rol que desempeñan en el mapa político uruguayo los partidos y movimientos sociales. A continuación reconstruimos el proceso conducente a la regulación del cannabis y analizamos mecanismos, roles, estrategias, repertorios de acción e interacciones entre actores político-partidarios y movimientos sociales. Evaluamos el proceso a la luz de dos modelos alternativos de diseño de políticas: de arriba hacia abajo (top-down) y de abajo hacia arriba (bottom-up) (Peters 1996). Emparentados con la distinción habermasiana entre iniciativas iniciadas en el centro o en la periferia del sistema político (Habermas 1996), estos dos enfoques enfatizan diferencialmente el rol del sistema político y los liderazgos, por un lado, y de las demandas sociales, por el otro. ${ }^{7}$ Concluimos con una reflexión acerca de la conjunción de factores que hicieron posible la regulación del cannabis en Uruguay. En desafio de la distinción rígida entre visiones alternativas y mutuamente excluyentes, subrayamos el rol del liderazgo presidencial -en el sentido que le 
da Fabbrini (2009) de liderazgo "relacional"- en ejercicio de su capacidad instituyente; la importancia del contexto partidario e institucional uruguayo, observable en la capacidad presidencial para alinear a los legisladores de su partido aún en contra de la mayoría de la opinión pública; y el rol de una demanda preexistente, movilizada y presente tanto en la sociedad civil como dentro del sistema político.

\section{Partidos políticos y movimientos sociales}

En contraste con la situación de desafección política y los déficits de representación (Rosanvallon 2017) que atraviesan a otras democracias de la región (y del mundo), donde los estallidos de crisis de representación han barrido con gobiernos, partidos e incluso con sistemas de partidos completos, en Uruguay los partidos mantienen un rol clave no solamente en la organización de la competencia electoral sino también en la producción y reproducción de las identidades políticas y en el procesamiento de las demandas sociales. Así, la acción política resulta en procesos de identificación colectiva en el sentido señalado por Pizzorno (1985), es decir, mediante la construcción y puesta en escena de identidades colectivas bajo múltiples formas, entre las cuales se destacan los partidos políticos. La volatilidad electoral es reducida -los electores tienden a mantenerse fieles de elección en elección- y no han aparecido hasta la fecha liderazgos outsiders de envergadura. A diferencia de lo ocurrido en otros países latinoamericanos, los liderazgos uruguayos -como el de José Mujica- se han fortalecido en el marco de sus partidos de origen y no contra ellos.

Más que por su estabilidad, sin embargo, el sistema de partidos uruguayo se ha caracterizado por su transformación gradual y controlada. El surgimiento, a principios de los años setentas, de un partido "desafiante", el Frente Amplio, acabó produciendo entre los años noventas y los 2000 un realineamiento político e ideológico que resultó en el actual sistema pluripartidista de dinámica bipolar. Actualmente el clivaje izquierdaderecha sigue siendo, más que en (casi) cualquier otro país de la región, una variable explicativa relevante; se ha señalado, sin embargo, que en los resultados electorales de 2009 y 2014 han incidido con fuerza creciente, junto con la variable ideológica, la valoración de la situación económica y del desempeño del gobierno (Canzani 2016; Buquet y Piñeiro 2014). ${ }^{8}$ Las encuestas detectan fisuras en el andamiaje político-partidario: al tiempo que conservan su rol de brújula ideológica e identitaria y permanecen incuestionados en tanto que organizadores de la competencia política, los partidos políticos han retrocedido en la estima ciudadana. Según sondeos recientes, en 2016 solo el 22\% de los uruguayos confiaba en los partidos políticos (un descenso de 12 puntos respecto de 2015). Algo similar ocurría con el Parlamento (26\%) y el Poder Judicial (35\%), muy lejos de la confianza depositada en los bancos $(65 \%)^{9}$ y en la policía $(52 \%)^{10}$.

En el terreno de las lealtades políticas, resalta un dato que puede estar preanunciando cambios importantes para las próximas décadas. El 40\% de los jóvenes de entre 18 y 29 
años (conocidos como “Generación Ceibal”, en honor del plan del mismo nombre que en los últimos años entregó una computadora a cada niño en edad escolar) no expresa preferencias políticas, según una encuesta de Radar de $2017 .{ }^{11}$ En paralelo con sus dificultades para operar un recambio generacional en sus liderazgos y cuadros de gobierno, el Frente Amplio enfrenta problemas para renovar sus votantes, ${ }^{12}$ aunque conserva todavía una mayoría relativa de las intenciones de voto. Lo que es más importante, sigue siendo un punto de referencia en materia de reinvidicaciones de derechos, lo cual genera dinámicas específicas en su relación con los movimientos sociales, viejos y nuevos.

\section{El Frente Amplio y la agenda de derechos}

Como partido que, a diferencia de los llamados "tradicionales", reivindica sus orígenes en "el movimiento social", el Frente Amplio en el poder ha mantenido estrechas relaciones tanto con las organizaciones representativas de los intereses de los trabajadores como con las constitutivas de los denominados nuevos movimientos sociales. Sus momentos de mayor acercamiento o alejamiento respecto de cada una de ellas coincidieron con su capacidad para reaccionar y dar respuesta a sus demandas -demandas de clase, de inclusión o de reconocimiento, pertenecientes a sucesivas capas geológicas de la historia contenciosa uruguaya y artífices de reposicionamientos entre y dentro de cada uno de los partidos políticos.

La gestión de estas diferentes demandas, viejas y nuevas, no siempre ha coexistido armónicamente dentro del partido de gobierno. Por el contrario, ha habido tensiones entre demandas atendidas y demandas insatisfechas, entre actores que han seguido sintiéndose representados y actores que han optando por alejarse de la coalición gobernante. En particular, las demandas "postmaterialistas" de reconocimiento de derechos motorizadas más recientemente por movimientos sociales han recibido el apoyo de los sectores más liberales del Frente Amplio al tiempo que han sido desmerecidas como "burguesas" por algunos sectores de la izquierda más ortodoxa. ${ }^{13}$

En el período inaugurado en 2005, con el ascenso del Frente Amplio, el Estado retomó protagonismo. El patrón redistributivo mejoró a partir de la puesta en práctica de un conjunto de reformas sectoriales, muchas de ellas en el área social (Antía, Castillo et al 2013). En un marco de crecimiento económico sostenido, se redujeron las tasas de desempleo, aumentaron los salarios y la informalidad cayó a sus niveles más bajos desde que se relevan estadísticas sobre cobertura de la seguridad social (Arim 2016). Ello se debió en gran medida a la restauración de la negociación colectiva entre Estado, empresas y sindicatos en un contexto de alta densidad y cobertura sindicales. Gracias a una profunda reforma tributaria que permitió financiar una batería de políticas laborales y sociales enfocadas en los sectores más vulnerables (niños, ancianos, minorías afrodescendientes, trabajadoras domésticas, etc.), el gobierno frenteamplista logró reducir significativamente la pobreza (de 15,4\% en 2002 a 5,7\% en 2014), la indigencia (de $2,5 \%$ a $0,9 \%$ ) y la 
informalidad laboral (de 40,7\% a 23.5\%), así como mejorar levemente la distribución del ingreso. ${ }^{14}$ Lo hizo, lejos de la retórica anticapitalista y antiimperialista de sus orígenes, mediante la introducción de cambios moderados de política económica.

El mismo proceso de moderación programática que catapultó al Frente Amplio al poder por la vía electoral y luego amenazó con provocar desprendimientos "por izquierda" en la coalición gobernante (y en sus aliados en el movimiento sindical) acabó volviéndolo más permeable a las nuevas demandas de derechos formuladas en términos genéricamente liberales y "progresistas". Así, el Frente Amplio pasó a representar una nueva sensibilidad y una apertura hacia un conjunto de valores laicos y postmaterialistas, en gran medida vinculados al placer, por completo ajenos a la retórica de la izquierda tradicional. ${ }^{15}$

Los gobiernos de Tabaré Vázquez y José Mujica constituyeron ventanas de oportunidad para el ascenso de la llamada "nueva agenda de derechos". Al igual que en otros países de la región, esta agenda fue liderada en Uruguay por organizaciones y movimientos sociales, pero encontró el apoyo de diversos sectores políticos, predominante pero no exclusivamente frenteamplistas. Convertido en caja de resonancia de las demandas sociales, el Congreso aprobó una sucesión de iniciativas vinculadas con esta nueva agenda, tales como la autorización de la adopción de niños por parejas homosexuales o en concubinato y la admisión de homosexuales en las Fuerzas Armadas, el derecho a la identidad de género y al cambio de nombre y sexo en documentos (todas ellas en 2009); la ley de salud sexual y reproductiva que incluyó la despenalización del aborto (2012); el matrimonio igualitario (2013); y diversas acciones afirmativas en defensa de la igualdad de género (como las cuotas de participación en cargos electivos) y de protección de las comunidades afro-uruguayas (2013), así como el desarrollo de un sistema integral de cuidados para personas en situación de dependencia (2015).

\section{El movimiento social pro-regulación}

Las primeras expresiones a favor de la regulación del cannabis en Uruguay se hicieron oír entre 1985 y 1989, es decir, en el primer quinquenio post-dictadura, cuando la juventud era (junto con las minorías sexuales, otro blanco favorito de la policía) víctima de rutina de las razzias.Aunque su consumo fuera legal, la violencia policial se redoblaba cuando había marihuana involucrada, y, dependiendo de la discreción del juez, los arrestos podían dar lugar a procesos judiciales y terminar en largos períodos de encierro. En el marco del aumento del consumo y el tráfico, el Ministerio del Interior justificaba el accionar policial como necesario para prevenir el delito.Así se fue instalando en los medios y en los imaginarios la cadena de equivalencias de sentido entre juventud, delito y consumo de drogas, y entre drogas legales e ilegales (Bayce 1990).

En reacción a estos atropellos nació la Coordinadora Anti Razzias (Aguiar 2012), acompañada de una potente renovación cultural que se expresó por medios diversos, desde los muros urbanos hasta la música y la palabra impresa. Desde entonces se empezó a 
conformar, no solo gracias a la acción de las organizaciones sociales sino también por medio de intervenciones públicas de legisladores de izquierda y de agrupaciones profesionales y de debates internos a los partidos (inclusive en el Partido Nacional, el más refractario a estas cuestiones), la batería de argumentos que se amplificarían durante el proceso conducente a la aprobación de la ley 19.172. Por ejemplo, que la marihuana fue de uso libre durante siglos, hasta que por razones no inocentes (intereses económicos, conveniencia política y cruzadas morales combinadas en proporciones variables en diferentes contextos nacionales) se impuso el prohibicionismo a comienzos del siglo pasado. Que otras drogas legales como el tabaco y el alcohol tienen sobre la salud consecuencias mucho más dañinas que la marihuana. Que la proporción de "usuarios problemáticos" es mínima en el caso del cannabis, y que solo ellos deberían ser socorridos del mismo modo en que lo son los adictos a otras sustancias. Que las que se cuentan por cientos y miles no son las víctimas de la adicción a la marihuana sino las de la lucha policial y judicial contra la droga (y del estigma que se le asocia). Que si se garantiza al usuario el acceso a una sustancia cuya calidad es controlada por el Estado, es posible combatir el mercado negro y desmantelar el narcotráfico (al menos en lo que se refiere al cannabis, ya que no es de esperar que los consumidores de drogas duras las abandonen en beneficio de la marihuana). Que solo en un espacio de legalidad es posible promover la circulación de información que fomente el consumo responsable. Que los usos industriales y medicinales de la planta, muchos de ellos aún apenas explorados, podrían contribuir a solucionar otros problemas. Y que, por encima de todas las cosas, debería regir la garantía del artículo 10 de la Constitución Nacional que afirma que "las acciones privadas de las personas que de ningún modo atacan el orden público ni perjudican a un tercero, están exentas de la autoridad de los magistrados". ${ }^{16}$

Aún cuando las razzias de los primeros años de la transición democrática habían quedado en el pasado, a comienzos del siglo XXI la criminalización de usuarios y cultivadores no cedía. Según la ley 17.016 de 1998, quedaba "exento de pena” quien "tuviere en su poder una cantidad razonable destinada exclusivamente a su consumo personal, con arreglo a la convicción moral que se forme el juez a su respecto”. Sin embargo, también penaba con un mínimo de veinte meses de prisión excarcelable la producción de sustancias "capaces de producir dependencia síquica o física", independientemente de las cantidades involucradas. ${ }^{17}$ En ese marco, la mayoría de los operativos policiales (gatillados a menudo por denuncias de vecinos) incautaban cantidades ínfimas de droga, y se centraban en cambio en el decomiso de plantas y la detención de sus propietarios hasta que el juez de turno desestimara las causas contra ellos. La ley dejaba enteramente a criterio del juez la definición de la cantidad de marihuana que habría de considerarse como "razonable" para el consumo personal, y la cantidad de personas presas por autocultivo ascendía a varios centenares. El absurdo de la situación fue recalcado por las organizaciones sociales por la vía del posicionamiento mediático de algunos casos emblemáticos como el de Alicia Castilla, de 66 años de edad, psicóloga, escritora y líder 
de opinión del movimiento pro liberación de la marihuana, que en 2011 permaneció detenida tres meses por posesión de plantas de cannabis y para quien la fiscalía llegó a pedir dos años de cárcel. ${ }^{18}$

\title{
El proceso político: juventudes, liderazgos, opinión pública y partidos
}

\begin{abstract}
Jóvenes de ayer y de hoy
En paralelo con el proceso arriba descripto, dentro del sistema político las primeras propuestas de regulación de la marihuana habían surgido en la década del noventa desde algunos sectores del Frente Amplio, específicamente la Vertiente Artiguista y la juventud del Partido Socialista, así como entre los sectores más liberales del Partido Colorado. ${ }^{19}$ Pero estas propuestas nunca habían avanzado dentro del sistema político.
\end{abstract}

A mediados de 2006, con el Frente Amplio ya en la presidencia, las juventudes socialista y artiguista comenzaron a promover abiertamente el debate, tanto dentro del Frente Amplio como frente a la opinión pública, desafiando los "tabúes y dobles discursos" predominantes, resultantes en la instalación de prácticas sociales legitimadas pero no cobijadas por el marco normativo (LR21, 21/08/06). ${ }^{20} \mathrm{~A}$ pocos días de lanzada la iniciativa de las juventudes partidarias, el Comité Ejecutivo Nacional del Partido Socialista se pronunció en favor de "apoyar el necesario e importante debate impulsado por su organización juvenil" y propugnar el cambio legal con el objeto de "combatir las prácticas empresariales de puntos de ventas clandestinos e inmorales que utilizan a la marihuana como variable de ajuste para fomentar el consumo de la pasta base". Una diputada del sector anunció que se realizaría "una jornada en el Parlamento en la que los jóvenes planteen el debate" de la legalización, ya que "ellos tienen que ser los protagonistas". Similares pronunciamientos se oyeron en boca de varios legisladores socialistas, de la Vertiente Artiguista y del Movimiento de Participación Popular (MPP) -pese a la convicción, entre estos últimos, de que "no es de los temas más importantes del país" (LR21, 26/08/06).

No sorprende que la demanda pro-legalización haya sido considerada en forma prácticamente unánime, tanto por observadores externos como por protagonistas del proceso, como una demanda “juvenil" o “generacional”. En la sesión de julio de 2013 en la cual el proyecto fue, ante la mirada atenta de las barras pobladas mayormente de jóvenes, finalmente aprobado, el legislador oficialista a cargo de la fundamentación de la iniciativa destacó el rol de "las juventudes progresistas del Frente Amplio, que hace ya más de veinte años que vienen planteando la necesidad de cambiar la política prohibicionista que ha signado todo lo que tiene que ver con las sustancias ilícitas". ${ }^{21}$

El comentario del diputado Sebastián Sabini, él mismo un joven de poco más de treinta años, daba en el clavo. La regulación había sido el resultado de un proceso de maduración lenta de una demanda social motorizada por jóvenes o, más exactamente, por quienes habían sido jóvenes cuando la demanda salió por primera vez a la superficie, en los 
primeros años de la restauración democrática (o que lo habían sido incluso antes, pero que habían visto sus activismos suspendidos por la proscripción, la cárcel y/o el exilio). Tras el ascenso del Frente Amplio en 2005, estos “jóvenes de ayer" habían pasado a ocupar cargos públicos tanto dentro de agencias de la órbita del Ejecutivo - ministerios, secretarías y organismos como la Junta Nacional de Drogas- como en el Parlamento: es decir, se habían convertido en actores claves para impulsar por canales institucionales y lograr la aprobación de la ley. A ellos se habían sumado, sobre todo desde la sociedad civil, nuevas generaciones de jóvenes procedentes de los claustros universitarios, organizados en asociaciones civiles y convocados a las calles por los nuevos movimientos sociales. Así, nuevas generaciones de profesionales y activistas, mucho más visibles en las calles que sus pares de mayor edad, compartieron cartel con viejos libertarios y cultivadores sexagenarios. La diversidad etaria de la coalición por la liberación del cannabis se vio reflejada en la composición de los primeros clubes cannábicos que obtuvieron reconocimiento legal, con socios de edades comprendidas entre los 25 y los 70 años. ${ }^{22}$

\section{El movimiento social: movilización callejera y saber experto}

La demanda de legalización/regulación del cannabis comenzó a articularse públicamente a poco de llegado el Frente Amplio al gobierno en $2005 .^{23}$ El 5 de mayo de ese mismo año se realizó una manifestación callejera en el marco de una convocatoria global, la Marcha Mundial de la Marihuana. La voz se corrió de boca en boca y la concurrencia no pasó de unos centenares de personas, situación que se repitió el año siguiente. Fue recién en 2007 cuando la demanda se hizo realmente visible por primera vez en el espacio público. La manifestación se realizó en unas doscientas ciudades del mundo; en Montevideo, con una cobertura mediática sin precedentes, más de 6000 personas se dieron cita en el barrio de Malvín. Se trató de una cifra inusual para una convocatoria liderada por actores ajenos a los partidos políticos. ${ }^{24}$ Estas manifestaciones, de creciente masividad, se repetirían cada mes de mayo hasta la aprobación de la ley de regulación del cannabis, e incluso (aunque ya con menor concurrencia) luego de aprobada la ley. ${ }^{25}$

Entre la cita de 2006 y la de 2007 había ocurrido un cambio organizativo clave: las tres organizaciones que lideraban el reclamo -Planta Tu Planta, La Placita y Prolegal- habían convergido en el Movimiento por la Liberación del Cannabis (Aguiar y Muñoz 2007). ${ }^{26}$ Más tarde, éste derivaría en la formación de una organización del mismo nombre, y el rol articulador pasaría a ser desempeñado por la Coordinadora por la Regulación del Cannabis.

La convergencia resultó altamente productiva en la medida en que distintas organizaciones aportaron diferentes argumentos: la regulación caso por caso (la separación de la marihuana respecto de las demás drogas), el debilitamiento del narcotráfico, la protección de la elección individual y la prescindencia del Estado, la importancia de la investigación de las propiedades medicinales del cannabis. Todas ellas, además, adoptaron desde sus orígenes una estrategia de visibilización con objetivos desestigmatizadores. Así, por 
ejemplo, en 2006, y nuevamente en 2007, La Placita convocó para el 23 de noviembre -el "Día Nacional del Porro"- a una "fumata pública" en Plaza Independencia por la legalización del autocultivo y la venta de marihuana (EE, 23/11/07).

En los años siguientes, el entramado organizacional pro-liberación del cannabis se volvería más denso: la coalición pasaría a incluir tanto a organizaciones de defensa del consumo y el cultivo como a organizaciones veteranas de otras luchas por los derechos humanos, como el Instituto de Estudios Legales y Sociales del Uruguay (IELSUR), y otras recién formadas pero con una visión amplia de los derechos "de última generación", como Proderechos. Todas ellas, junto con las organizaciones de la diversidad sexual, la Federación de Estudiantes Universitarios, el Departamento de Jóvenes de la central sindical (PIT-CNT), y las juventudes partidarias, trabajarían juntas en el marco de la Coordinadora Nacional por la Regulación del Cannabis.

Las organizaciones que integraron la coalición pro-regulación movilizaron no solamente seguidores sino también saber experto acumulado a partir de la experiencia directa con la planta y con la política antidrogas en el país, el estudio de la experiencia regulatoria en otros países, y los intercambios con especialistas internacionales en salud, seguridad y política de drogas que habían tenido cierto protagonismo en las etapas iniciales del "experimento" uruguayo (Müller Sienra y Draper 2017). ${ }^{27}$

En abril de 2010 la Cámara de Diputados estableció una Comisión Especial de Adicciones (P180,11/04/10). En los años subsiguientes, diversas organizaciones y activistas de la Coordinadora Nacional desfilarían ante la comisión, al igual que numerosos profesionales y especialistas en salud y política de drogas. En agosto de 2011 tuvo lugar el primer Debate Nacional sobre Drogas, organizado por Proderechos, IELSUR y El Abrojo, y auspiciado por varias agencias gubernamentales y cooperantes internacionales como la Open Society Foundations. ${ }^{28}$ Allí quedaron plasmados los argumentos y delineados los actores que llevarían hasta el final la iniciativa de regulación. A los argumentos proderechos, que enfatizaban especialmente la habilitación del autocultivo, se agregaron entonces, por un lado, los vinculados con la agenda de seguridad y, por el otro, los de naturaleza económica. De hecho, también estuvieron presentes los representantes de las farmacias con un reclamo de participación en la comercialización del cannabis.

También en 2011 se formó una nueva asociación civil, la Asociación de Estudios del Cannabis del Uruguay (AECU), ${ }^{29}$ orientada a la investigación y difusión de información sobre el cannabis. Poco a poco el soporte académico del movimiento se completaría con el establecimiento de nuevos grupos de estudio e investigación, tales como el Núcleo Interdisciplinario de Estudios sobre Cannabis alojado en la Universidad de la República, y la Iniciativa Latinoamericana de Investigación sobre Marihuana integrada por académicos de la Universidad Católica del Uruguay. 
Finalmente, mientras maduraba el diseño de una campaña para presentar el tema de un modo que resultara "aceptable" para una opinión pública aun adversa, surgió en 2013 una nueva organización, Uruguay por la Regulación Responsable de la Marihuana. Bien lejos de los estereotipos comúnmente asociados a la marihuana, la campaña de opinión pública que vio la luz en junio de ese año enfatizó aspectos relacionados con la salud, la seguridad y la educación (Müller Sienra y Draper 2017). Entretanto, el movimiento se desplegaba estratégicamente en los medios de comunicación para informar con datos fehacientes, desmontar prejuicios, disipar malentendidos y desactivar temores. ${ }^{30}$

\section{Liderazgo presidencial y opinión pública}

En 2012 el contexto regional -caracterizado por el aumento del crimen violento asociado al narcotráfico y los crecientes cuestionamientos de la política antidrogas promovida desde los Estados Unidos, el principal mercado consumidor- era particularmente propicio para el lanzamiento del "experimento uruguayo". En febrero de ese año, el presidente de Guatemala, un país asolado por la violencia homicida vinculada con el tráfico de drogas, había propuesto que la subregión centroamericana debatiera la posibilidad de despenalizar las drogas. En abril, en su sexta cumbre celebrada en Cartagena, Colombia, los jefes de Estado de las Américas encomendaron a la OEA la confección de un informe sobre la lucha antidrogas en la región.

Dos meses después el presidente Mujica, preocupado por el problema del aumento del consumo de pasta base en el país, presentó en Uruguay la idea de experimentar, para el bien del continente y de la humanidad, con una política nueva para la marihuana. La idea era que, por las características y dimensiones del país, aún si la política fracasara sus consecuencias negativas serían relativamente acotadas y fácilmente reversibles. Menos de un año más tarde la Secretaría General de la OEA publicaba su informe sobre "El problema de las drogas en las Américas", que para el caso de la marihuana reconocía la existencia de tendencias a la despenalización y apelaba a la flexibilización de las posturas adoptadas hasta entonces. ${ }^{31}$

En junio de 2012 el presidente Mujica se puso al frente de una iniciativa de regulación de la marihuana que, como hemos visto, llevaba años en circulación. Esta apropiación supuso una reformulación: a la demanda del movimiento social en torno de la habilitación del autocultivo - es decir, de la ampliación de la esfera de la libertad individual por medio de la introducción de una garantía de no injerencia indebida del Estado- le sumó una propuesta inédita: generar un mecanismo alternativo para acceder a la sustancia mediante la asignación al Estado de responsabilidad sobre y control de la cadena completa de producción y distribución. Preocupado por la creciente penetración del narcotráfico, el avance alarmante del consumo de pasta base de cocaína, muy barata y adictiva, entre los jóvenes de menores recursos, el aumento de los delitos cometidos por adictos con el objeto de abastecerse de la droga, y la superpoblación y las malas condiciones carce- 
larias -en otras palabras, por el fracaso de la política de "guerra contra las drogas" y del prohibicionismo en general- el presidente sostuvo su propuesta en una reivindicación de la experimentación. Esta fue recibida con un avalancha de críticas desde la oposición, que la denunció como -en el mejor de los casos- una maniobra de distracción.

La opinión pública no lo acompañó. Según una encuesta de Cifra de julio de 2012, el 66\% de los uruguayos se oponía a la iniciativa y solo $24 \%$ la aprobaba. En otra encuesta realizada entre fines de noviembre y principios de diciembre del mismo año, cuando ya se habían dado a conocer algunos detalles adicionales del proyecto, el 64\% se mantenía en desacuerdo y solo el $26 \%$ se manifestaba de acuerdo. Entre quienes rechazaban el proyecto se contaban el 83\% de los votantes del PN, el 82\% de los del PC y el 53\% de los del FA (con, entre los últimos, una minoría de 35\% a favor).Y si bien la aceptación de la medida disminuía con la edad y aumentaba con el nivel educativo, el 53\% de los jóvenes adolescentes y veinteañeros, así como el 58\% de los universitarios, también rechazaban la iniciativa. ${ }^{32}$

El liderazgo de Mujica en este tema fue de tipo instituyente más que representativo: no pretendió "representar" en el sentido literal del término, desde abajo hacia arriba, dando voz a una demanda ya existente en la opinión pública, sino más bien instituir desde el vértice contribuyendo a la formación de una demanda nueva (existente en una pequeña minoría movilizada en torno del tema, pero no en calidad de demanda general atribuible a "la sociedad" o "la ciudadanía"). En los términos de Fabbrini (2009), el liderazgo presidencial se activó para encauzar el proceso decisional. De ahí que el presidente se embarcara en una intensa campaña mediática para desmentir acusaciones, disipar fantasmas y esclarecer las cuestiones en juego. Una y otra vez aseguró a la ciudadanía que el gobierno no pretendía fomentar adicciones ni convertir al país en un paraíso para turistas aficionados el consumo recreativo, sino en cambio ofrecer una medida con alguna chance de poner freno al ascenso del narcotráfico y al aumento del consumo de pasta base. "La violencia creciente en nuestra sociedad tiene una ligazón directa o indirecta enorme con la proliferación de la metodología en la que incurre precisamente el narcotráfico. Mucho más graves que los daños innegables que hacen a la salud humana las drogas, mucho peor es el resultado en la sociedad, en el narcotráfico", señalaba Mujica en el mes de julio (IB, 19/07/12). De lo que se trataba era de regular-es decir, de poner cierto orden en- una situación preexistente, que ocurre "delante de nuestras narices, en una esquina, en las puertas de los liceos”, precisaba pocos días más tarde (Audición radial M24, 1/08/13). "El problema grave es el narcotráfico, no la marihuana", sintetizaba en agosto en una entrevista en la cual también afirmaba que la tercera parte de los 9 mil presos de Uruguay estaba detenido por situaciones vinculadas al narcotráfico (CNN, 26/08/12). Este era el punto neurálgico de la argumentación, en la medida en que la opinión pública que se inclinaba mayoritariamente contra la regulación del cannabis era la misma que reclamaba con insistencia mejoras en el terreno de la seguridad. 


\section{La disciplina partidaria al rescate}

Tal como había ocurrido un año antes en ocasión de la aprobación de la ley de interrupción voluntaria del embarazo (Pousadela 2016), la línea divisoria que la cuestión de la liberación del cannabis marcó en el terreno político no se correspondió estrictamente con el clivaje partidario. Si bien tanto los partidos tradicionales como el Frente Amplio estaban mayoritariamente alineados a uno y otro lado de la iniciativa, ninguno de ellos se comportó monolíticamente durante el debate. Pese a que la iniciativa procedía de sus filas, el Frente Amplio enfrentó dificultades para reunir los votos de todos sus diputados, necesarios para aprobarla. Debió, en consecuencia, echar mano de un recurso poco común entre los partidos contemporáneos: la apelación a la disciplina partidaria.

En efecto, en la Cámara de Diputados la iniciativa estuvo a punto de naufragar porque un diputado frenteamplista de la Liga Federal se negaba a votarla. Otro diputado, de la corriente frenteamplista Frente Izquierda de Liberación (FIDEL), oponía reparos, pero aseguró que acataría el mandato de la bancada o de la Mesa Política del Frente Amplio. El primero, en cambio, se negaba a acatar mandatos argumentando que "esto no es una cuestión de principios para el FA, no está ni en la carta fundacional y tampoco estaba en el programa de gobierno. Es más, ni siquiera escuché a uno de los candidatos decir que íbamos a vivir en un país donde las drogas estén liberadas" (EP, 10/04/13). Tras varios meses de conversaciones y negociaciones que resultaron en la incorporación de algunas modificaciones, este diputado se avino a votar afirmativamente el proyecto, pero en su discurso insistió en que la marihuana "es una bosta con o sin ley" y en que se trataba de un "proyecto cupular", ya que "no nació en el seno del pueblo, tampoco -que yo sepa- en el corazón de un comité de base y tampoco se discutió al principio en la fuerza política. Esto nació en el Poder Ejecutivo, en las alturas [...] exactamente al contrario que cómo debía nacer" (Diario de Sesiones, 31/07/13).

Del otro lado, algunos diputados de otros partidos habían adelantado una opinión favorable a la legalización, o al menos la regulación, del consumo de marihuana. Un diputado joven del Partido Colorado, uno de los primeros legisladores en proponer la legalización del autocultivo, tuvo críticas para el registro de consumidores que proponía la ley, pero se manifestó dispuesto a votarla (P180,14/05/13). Por su parte, otro diputado colorado, joven también y fiel a las fuentes liberales clásicas de su partido, defendió el consumo como "un acto de libertad sobre el que nunca, nunca, puede intervenir poder alguno, en tanto no comprometa a terceros" e insistió en que "lo que se hace en la alcoba, en el sagrado inviolable que es el hogar" no debe ser prohibido. En ese sentido opinó que "el uso no debe ser un problema, lo que tenemos que trabajar es el abuso y es en el marco de la ley que el Estado puede proteger a la sociedad"; finalmente, en respuesta al exabrupto del frenteamplista díscolo, dijo que "una bosta, precisamente, sería que miráramos para el costado mientras miles de ciudadanos son adictos a la pasta base y nosotros frívolamente estamos discutiendo sobre el consumo de cannabis, cuando es nuestra obligación constitucional y 
política regular para proteger a la sociedad”. Sin embargo, declaró que "a pesar de compartir el principio de la solución" no votaría a favor del proyecto "porque hay una disciplina partidaria, la misma que hace que algunos que piensan distinto a mí terminen votándolo. Como hombre de partido, esto lo respeto; los partidos políticos son comunidades de ideas y la unidad de acción es lo que garantiza ese sistema" (Diario de Sesiones, 31/07/13).

Algo similar ocurrió con un lesgislador del Partido Independiente que aseguró tener "una predisposición favorable a votar la legalización de la marihuana y no me parece que la ley sea un mamarracho como se ha dicho" (EP, 10/05/13), pero en la Cámara se plegó a la decisión de su partido de no acompañar la votación y, de resultar aprobado el proyecto, de votar afirmativamente los artículos vinculados al autocultivo, la creación de los clubes de membresía y la promoción de la salud y la educación. Con críticas más profundas a la iniciativa, también el diputado y candidato a la presidencia por el Partido Nacional, Luis Alberto Lacalle Pou, anunció que el pronunciamiento de su partido sería negativo en la votación en general, pero afirmativo en relación con los artículos referidos al autocultivo. Lacalle Pou llevaba años en la defensa del autocultivo, y en 2011 había presentado al respecto un proyecto de ley que no había sido considerado.

En la Cámara de Diputados la ley fue aprobada en general con 50 votos sobre 92 . Como resultado del disciplinamiento arriba descripto, todos los votos a favor de la iniciativa procedieron del Frente Amplio, mientras que todos los votos en contra procedieron de los partidos tradicionales. En algunos puntos, y particularmente en relación con el autocultivo, el nivel de aprobación (60 sobre 89 presentes) fue mayor como resultado de la confluencia de votos blancos, colorados y del Partido Independiente.

En el Senado todos los frenteampistas adhirieron al proyecto. La oposición fue liderada por el presidente del Directorio del Partido Nacional, quien se manifestó a favor del autocultivo pero criticó el proyecto por excesivamente reglamentarista. Mientras se discutía la iniciativa, afuera del recinto tenía lugar la que se dio en llamar "la última marcha con la marihuana ilegal”, con cientos de manifestantes que vitoreaban la aprobación (LD, 11/12/13).

\section{Conclusiones: ¿Una ley muy uruguaya?}

Según una investigación de Chasquetti (2014) el 35\% de las leyes aprobadas entre 2010 y 2013 llevaba la firma de legisladores del Frente Amplio, ${ }^{33}$ y 81 de los 166 proyectos presentados con firma de legisladores frenteamplistas lograron convertirse en ley. ${ }^{34}$ En otras palabras, mientras que los proyectos iniciados por la oposición sin la colaboración del Frente Amplio tuvieron una probabilidad de apenas 9\% de ser convertidos en leyes (10\% para los del Partido Nacional, 5\% para los del Partido Colorado), dicha probabilidad fue de casi $50 \%$ para los iniciados por legisladores oficialistas. 
En ese escenario, ¿cuáles fueron los factores que, en el caso de la regulación del cannabis. inclinaron la balanza hacia la aprobación? No pocos actores involucrados, y particularmente los opositores más tenaces y los legisladores frenteamplistas díscolos, subrayaron la "imposición" del Ejecutivo. También diversos autores, tales como Queirolo, Repetto y Rossel (2017), teorizaron acerca del carácter top-down del proceso.

Lejos de ser lineal, sin embargo, el camino que describe este trabajo es largo y sinuoso. La designación del proceso de aprobación de la ley como una imposición desde arriba hacia abajo es una simplificación unilateral de una realidad más compleja. Tal como lo señalamos en las secciones precedentes, el liderazgo presidencial y su capacidad para alinear a sus legisladores bajo el signo de la disciplina partidaria fue un factor extremadamente relevante: si la ley 19.172 no resultó de un proceso top-down, ciertamente tampoco fue el resultado de un proceso bottom-up, con fuerzas sociales que torcieran el brazo de los poderes del Estado para obtener respuesta a su demanda. El presidente efectivamente hizo propia la iniciativa de regulación y la llevó adelante aún contra la posición desfavorable de la mayor parte de la opinión pública. Pero esa iniciativa tenía forma y estado público con anterioridad e independencia de su apropiación por parte del presidente: era una demanda preexistente de un sector de la ciudadanía organizada con expresiones tanto en la sociedad civil como dentro del sistema político.

El aporte diferencial de la intervención de liderazgo presidencial no radicó en el convencimiento de la opinión pública sino en el realineamiento de la tropa legislativa: para la fecha de la aprobación de la ley las encuestas seguían indicando que la mayoría se oponía a la marihuana legal. En otras palabras, ni el activismo del movimiento social ni las intervenciones presidenciales habían logrado hasta entonces mover la aguja de la aprobación popular. ${ }^{35}$ Mientras que la ciudadanía activa (la ciudadanía organizada en asociaciones civiles, grupos de activismo y movimientos sociales) se había expresado inequívocamente a favor, la ciudadanía pasiva o ciudadanía-opinión, expresada reactivamente en las encuestas, seguía posicionándose mayoritariamente en contra de la iniciativa.

El presidente Mujica hizo propia la demanda preexistente del movimiento pro-regulación porque la percibió (erróneamente, según muchos de los propios portadores originales de dicha demanda) como una respuesta a su búsqueda de soluciones alternativas al problema de la inseguridad y el narcotráfico. Sin embargo, la ley eventualmente votada por el Parlamento se parecía bastante poco a la versión originalmente presentada por el Poder Ejecutivo. En efecto, el proyecto inicial de Mujica, presentado en agosto de 2012 constaba de un solo artículo ${ }^{36}$ y no contemplaba ninguno de los mecanismos específicos que acabó conteniendo la ley 19.172. La distancia entre el proyecto original del presidente y la ley finalmente aprobada fue la medida exacta del trabajo de las organizaciones sociales pro-regulación que lideraron el reclamo por el autocultivo y pusieron su saber experto al servicio del proceso legislativo. 
En suma, la ley 19.172 fue el resultado de las interacciones entre actores que acabaron alineándose por razones marcadamente diferentes - de seguridad y disputa de mercados al narcotráfico, de salud y reducción de daños, de derechos y libertades individuales. Tres factores centrales dieron cuenta del resultado final: el liderazgo presidencial; la centralidad de un partido político enraizado, disciplinado y con fuertes conexiones con los movimientos sociales; y la labor de un movimiento social que articuló su reclamo en el lenguaje de los derechos y combinó el trabajo institucional con la presencia, mayoritariamente juvenil, en las calles.

En el marco de un sistema político altamente institucionalizado, el movimiento social se vio compelido a diversificar sus estrategias para canalizar sus demandas por vías institucionales. Así, mientras algunos centenares (y, en el punto álgido, unos cuantos miles) de activistas salían a la calle y daban presencia pública al movimiento, las organizaciones sociales aportaban su saber experto a la maquinaria de la política institucional, proveyendo insumos sustantivos para la producción de legislación, soluciones prácticas y monitoreo de la implementación de las regulaciones. ${ }^{37}$

En el palacio o en la calle, la brújula del movimiento social fue la "agenda de derechos": de ahí la colocación de esta iniciativa,junto con otras que marcaron el debate público en años recientes, en línea con avances en materia de derechos como la ley de divorcio o el sufragio femenino, que colocaron a Uruguay en la vanguardia mundial en el siglo XX. Sin embargo, el argumento de los derechos coexistió pacíficamente con el discurso utilitario que, lejos de valorar la apertura de nuevos espacios de goce y libertad individuales, vio en la legalización del cannabis un instrumento para otros fines, ya fuera la derrota del narcotráfico, la minimización de daños en materia de salud pública o, lisa y llanamente, la apertura de oportunidades de negocios. De hecho, el movimiento social pro-legalización pareció reconocer que, en ausencia de ventajas adicionales que supusieran oportunidades económicas para los privados y réditos políticos para el Estado posiblemente no hubiera habido voluntad política ni consenso para impulsar la regulación. Reveló así la clave principal que da cuenta del éxito del lanzamiento de este experimento uruguayo: la formación de equilibrios en virtud de los cuales una pluralidad de actores acaba consiguiendo, cada uno de ellos, (un poco de) lo que buscaba: más mercado, más Estado, más libertad. 
${ }^{1}$ Una versión preliminar de este artículo fue presentada con el mismo título en el Seminario de Investigación de la Escuela de Política y Gobierno de la Universidad Nacional de San Martín. Las autoras agradecen los aportes recibidos de los comentaristas y asistentes al evento.

${ }^{2}$ La ley habilitó el cultivo tanto de cannabis de efecto psicoactivo con fines recreativos, medicinales y de investigación científica, como de cáñamo (variedades de cannabis sin efecto psicoactivo) para la industria textil, cosmética, de la construcción, el papel y los biocombustibles. Los usos medicinales, en particular, fueron muy enfatizados a lo largo del proceso, aún por quienes impulsaban la legalización por razones estrictamente recreativas, en la medida en que el respaldo de la ciencia y su labor en pos de la eliminación del dolor y la cura de enfermedades -fines generalmente percibidos como superiores a la búsqueda de entretenimiento y placer- permitía jerarquizar el reclamo a los ojos de la opinión pública. Sin embargo, la reglamentación avanzó primero en el terreno del cannabis recreativo, mientras la producción y la venta de aceite de cannabis medicinal seguían bajo estudio del Ministerio de Salud Pública. Cf. Ley N 19.172, "Marihuana y sus derivados. Control y regulación del Estado de la importación, producción, adquisición, almacenamiento, comercialización y distribución", disponible en http://goo.gl/k7moaa.

${ }^{3}$ Entrevista en Expo Cannabis, Montevideo, 8/12/15.

${ }^{4}$ Audición Radial M24, "Mujica sobre marihuana: 'Estamos haciendo un experimento de vanguardia en el mundo entero"”, 1/08/13, en https://www.presidencia.gub.uy.

${ }^{5}$ A poco de iniciarse, sin embargo, la venta en farmacias quedó en entredicho como resultado de la intervención de los bancos internacionales, y en particular estadounidenses, que anunciaron su negativa a operar con farmacias que vendieran el producto o con entidades bancarias locales que operaran con tales farmacias, con clubes de cannabis o con las empresas que tienen la concesión para producir marihuana.

${ }^{6}$ Los clubes de cannabis -o, en la terminología del IRCCA, "clubes de membresía"- son organizaciones civiles constituidas con el objeto de producir flores de cannabis psicoactivo destinado al consumo de sus miembros. Según las regulaciones que se les aplican, estos clubes deben contar con entre 15 y 45 socios, todos ellos personas físicas mayores de edad con ciudadanía legal o natural uruguaya o con residencia permanente en el país. Cada club tiene permitido cultivar 99 plantas hembra, con un máximo de producción y acopio de 480 gramos anuales por socio, y debe contar con un responsable técnico a cargo de asegurar el cumplimiento de toda la normativa vigente. Para mayor información, véase IRCCA, "Clubes de Membresía”, en http:// www.ircca.gub.uy/clubes-de-membresia/.

${ }^{7}$ En palabras de Peters (1996: 259-60), según el primer enfoque "el público se involucraría principalmente a través del proceso electoral y quizá mediante el cabildeo con los legisladores, pero este involucramiento sería en gran parte indirecto y ocurriría más bien al principio del proceso. Por otra parte, el proceso político de abajo hacia arriba supondría que la puesta en práctica debería estar en función de los deseos y capacidades de los niveles inferiores del gobierno y de sus clientes. Supondría, además, que todo el proceso de la política pública debería organizarse para reflejar de manera más directa las demandas de lo que constituye 'la arena' de elaboración de políticas, así como los deseos de las masas. La formulación de las políticas públicas se abriría a diferentes influencias, en vez de reflejar principalmente las ideas de los funcionarios elegidos y nombrados". ${ }^{8}$ Según las encuestas, los uruguayos diferencian claramente la orientación ideológica de la gestión gubernamental. Así, por ejemplo, hacia 2016 la mayoría (52\% contra 46\%) valoraba positivamente el rumbo del gobierno frenteamplista, mientras que la gestión concreta era mucho peor valorada: en 2015 era considerada positivamente por el $40 \%$, cifra que descendió a $12 \%$ en 2016. Es decir, una proporción importante de la ciudadanía mantenía su apoyo ideológico aunque no respaldaba las decisiones políticas del gobierno (Bottinelli 2016b).

${ }^{9}$ Cabe señalar que la elevada confianza en los bancos está asociada con la posición del Banco República (Bottinelli 2016a). Como lo aclara el analista de opinión pública Oscar A. Bottinelli, las cifras arriba citadas dan cuenta de la gran confianza de los uruguayos en el Estado, confianza que registra un aumento en relación con años anteriores. Es decir, los uruguayos trazan una línea de división clara entre gobierno y Estado, así como entre los distintos poderes de Estado. Esto podría tener relevancia a la hora de entender el rol regulatorio asignado al Estado en relación con el cannabis. Cf. Factum Digital, 21/10/16, “Cuando no coinciden la valoración del rumbo gel gobierno y de la gestión del gobierno”, en http://goo.gl/FoLas6.

${ }^{10}$ Cf. Factum, septiembre de 2016, "El ranking de confianza en instituciones", en http://goo.gl/M2AckU.

${ }^{11}$ Cf. Montevideo Portal, 24/05/17, "Encuesta de Radar revela una leve ventaja del Frente Amplio sobre el Partido Nacional”, en http://goo.gl/8qdaHU.

${ }^{12}$ Estas dificultades se vieron intensificadas en tiempos recientes por las denuncias de corrupción contra el Vicepresidente de la República, Raúl Sendic, y su eventual renuncia, requerida por sectores del propio Frente Amplio.

${ }^{13}$ Se trata, en gran medida, de sectores de la "vieja guardia": funcionarios que iniciaron su activismo en una época en que las izquierdas latinoamericanas trataban a la homosexualidad como una desviación y a la droga como una forma más de la alienación capitalista - "opio del pueblo"- y para quienes estas demandas cons- 
tituyen frivolidades posmodernas distractivas de la "contradicción principal”, la de clase. En el caso que nos ocupa, sin embargo, cabe subrayar que fue uno de los integrantes de esa vieja guardia, el entonces Ministro de Defensa Eleuterio Fernández Huidobro, quien convenció al presidente Mujica de liderar la regulación de la marihuana mediante la inclusión de la iniciativa dentro de un paquete de medidas de seguridad ciudadana y lucha contra el narcotráfico.

${ }^{14}$ Según la CEPAL (2015) el índice de Gini pasó de 0,455 en 2002 a 0,379 en 2014.

${ }^{15}$ De ahí las reacciones conservadoras no solamente de los partidos tradicionales sino también dentro del propio Frente Amplio, donde fue liderada por figuras procedentes de la izquierda más ortodoxa.

${ }^{16}$ A lo largo de la última década muchos de estos argumentos, si es que no todos, fueron planteados en la revista argentina THC, también publicada en Uruguay. Cf. http://www.revistathc.com.

${ }^{17}$ Ley $\mathrm{N}^{\circ} 17.016$ sobre estupefacientes, disponible en http://goo.gl/vYZrqZ.

${ }^{18}$ Cf. Cannabis Magazine, s/f, “Alicia Castilla, presa por cultivar marihuana”, en http://goo.gl/3XqZdj.

${ }^{19}$ En el año 2000, a poco de iniciado su gobierno, el último presidente Colorado, Jorge Batlle, había anunciado su intención de promover la legalización del consumo de marihuana, pero luego había retrocedido sobre sus pasos (LR21, 26/08/06).

${ }^{20}$ El reclamo partía de la necesidad de contar con estrategias diferenciales para diferentes sustancias -básicamente, "separar la marihuana del resto de las drogas"-, así como de diseñar políticas integrales con un fuerte énfasis en sus aspectos sanitarios y educativos. Señalaba, asimismo, que el consumo más problemático involucraba "drogas legales" (en particular el alcohol) en mucha mayor medida que a la marihuana. En el caso de los socialistas, un argumento importante se centraba en la necesidad de controles estatales sobre la oferta y la calidad de la droga.

${ }_{21}$ Cf. Diario de Sesiones del Parlamento Uruguayo Número 3874, 21/07/13, disponible en http://goo.gl/ adQe86. Véase también el registro audiovisual del cierre de la sesión en http://goo.gl/uoEQrn.

${ }^{22}$ El dato corresponde al Club Cannábico El Piso; véase http://goo.gl/8UXkwH. Adicionalmente, a poco de inaugurada la venta de marihuana en farmacias se informó que el 70\% de los inscriptos tenía más de 30 años de edad (EO, 19/07/17).

${ }^{23}$ La política "knock out a las drogas", lanzada por el recién inaugurado gobierno de Vázquez en agosto de 2005, contenía componentes educativos, sanitarios y recreativos, y se centraba en la lucha contra el "consumo problemático" (LR21, 18/08/05).

${ }^{24}$ Cf. Universia, 8/05/07, "Derechos y libertades sobre la mesa”, http://goo.gl/t7vvXY.

${ }^{25}$ Para la última marcha previa a la aprobación de la ley, véase https://www.youtube.com/watch?v=60AIis8wLo. La más reciente tuvo lugar en mayo de 2017 bajo el lema "Si no marchamos, nada se pone en marcha", y centró su reclamo en la efectiva implementación de la ley (MP, 5/05/17).

${ }^{26}$ Planta Tu Planta era una comunidad virtual de cultivadores formada alrededor de 2005; La Placita se había originado en 2006 a partir de un grupo informal que se reunía a fumar y conversar en una plaza del barrio de Buceo; y Prolegal se había constituido en 2006 en reacción contra la detención de un grupo de jóvenes por posesión de plantas. Con un discurso enmarcado en la "nueva agenda de derechos", esta última derivó rápidamente en la actual Proderechos.

${ }^{27}$ Para una definición de concepto de saber experto y ejemplos de los modos en que los movimientos sociales participan de los procesos de elaboración de políticas públicas interactuando con, accediendo a, y desplegando conocimiento experto, véase Orsini y Smith (2010).

${ }^{28}$ Cf. Presidencia, 24/08/11, "Debate Nacional sobre Drogas también es parte de la pelea por la integración y la equidad", en http://goo.gl/w1d6kE.

${ }^{29}$ Cf. Mapeo de la sociedad civil - Repertorio de organizaciones, en http://www.mapeosociedadcivil.uy/ organizaciones/asociacion-de-estudios-del-cannabis-del-uruguay/.

30 Véanse en ese sentido las entrevistas con Juan Vaz, vocero de la AECU, en MP, 11/06/15, disponible en http://goo.gl/9u1b7r; y con Bruno Calleros, del Movimiento por la Liberación del Cannabis, en LD, 5/05/17, disponible en http://goo.gl/XHYgDS. Una vez inaugurados los primeros clubes de autocultivo también abundaron las producciones audiovisuales y apariciones televisivas de representantes de tales asociaciones. Cf. por ejemplo las entrevistas con Gustavo Robaina, de Proderechos, en TNU, el canal público de televisión abierta, disponible en http://goo.gl/r8iEE8; y con Julio Rey, de la Federación de Cannabicultores del Uruguay, en el programa de la mañana "Desayunos informales", disponible en http://goo.gl/zfFJeR.

${ }^{31}$ Cf. OEA (2013) El problema de las drogas en las Américas. Washington DC: OEA. Disponible en http://goo.gl/I0Aby. ${ }^{32}$ Véase Cifra, "Marihuana”, 2/09/15, en http://goo.gl/8663sR.

${ }^{33} \mathrm{El} 30 \%$ de las leyes aprobadas en el período fueron patrocinadas por múltiples partidos, entre ellos el partido de gobierno, y el 26\% fueron iniciadas por legisladores del Partido Nacional. Solo el $7 \%$ fueron iniciativa del Partido Colorado; el Partido Independiente no consiguió convertir en ley ninguno de sus proyectos. Cf. Chasqueti (2014). 
${ }^{34}$ A la inversa, uno solo de los 20 proyectos presentados por múltiples partidos sin el concurso del Frente Amplio logró convertirse en ley, y tan solo 44 de los 483 proyectos presentados por legisladores de alguno de los partidos de oposición acabaron convertidos en leyes. Cf. Chasqueti (2014).

${ }^{35}$ Años más tarde, avanzado el proceso de reglamentación y con la marihuana a punto de salir a la venta en farmacias, la proporción se había invertido: las catástrofes anunciadas por los opositores a la iniciativa no se habían producido y el $68 \%$ de los uruguayos consideraba al consumo recreativo de marihuana como un derecho y apoyaba la ley (Mendiburo-Seguel et al 2017).

${ }^{36}$ Dicho artículo establecía que "el Estado asumirá el control y la regulación de las actividades de importación, producción, adquisición a cualquier título, almacenamiento, comercialización, y distribución de marihuana o sus derivados, en los términos y condiciones que al respecto fije la reglamentación". Cf. Presidencia, 8/08/12, Proyecto de ley establece marco normativo que permite regular el mercado de cannabis, en http://goo.gl/QgxJkB.

${ }^{37}$ De hecho, desde la aprobación de la ley el evento-insignia del movimiento pro-legalización/autocultivo no es una convocatoria callejera sino -tal como lo define su página web- "un encuentro", Expo Cannabis. Organizado por Uruguay Siembra, la primera plataforma de información y articulación sobre el cannabis y el cáñamo, el evento se realiza en un predio de exposiciones e incluye charlas, talleres, foros de debate, conferencias de expertos, consultorios de orientación, proyección de documentales, música en vivo, merchandising, centros de información y puestos de venta.Al igual que en el proceso de debate público y negociación política que condujo a la aprobación de la Ley 19.172, coexisten en el evento actores estatales tales como la Junta Nacional de Drogas, el IRCCA y la Intendencia Municipal de Montevideo, organizaciones sociales, organizaciones de promoción de la investigación del uso terapéutico del cannabis en enfermedades raras, bancos de semillas, grupos de investigadores, publicaciones periódicas, entidades académicas, empresas privadas y usuarios de todas las edades, emprendedores, activistas y académicos locales e internacionales. Cf. Pousadela y Lissidini (2015). 


\section{Referencias bibliográficas}

Aguiar, Sebastián y Carlos Muñoz (2007) Movimientos sociales juveniles en Uruguay. Informe de la situación tipo 2: Movimiento por la legalización del cannabis, Grupo de Estudios Urbanos y Generacionales (GEUG). Disponible en http://www.geug.edu.uy.

Aguiar, Sebastián (2012) "Movimientos sociales juveniles en Uruguay: Situación en las últimas décadas y escenarios prospectivos", en RECSO-Revista de Ciencias Sociales Vol. 3: 28-66. Montevideo: Universidad Católica del Uruguay.

Antía, Florencia, Marcelo Castillo et al. (2013) "La renovación del sistema de protección uruguayo: el desafio de superar la dualización", en Revista Uruguaya de Ciencia Política 22 (2): 171-194.

Arim, Rodrigo (2016) La negociación colectiva. Algunas reflexiones para el Uruguay de hoy, Serie Estudios y Perspectivas No. 21, Montevideo: CEPAL.

Bayce, Rafael (1990) Drogas, prensa escrita y opinión pública. Montevideo: Fundación de Cultura Universitaria.

Buquet, Daniel y Rafael Piñeiro (2014) "La Consolidación de un Nuevo Sistema de Partidos en Uruguay", en Revista Debates, Porto Alegre,Vol. 8, N¹: 127-148.

Bottinelli, Oscar A. (2016a) "El ranking de confianza en instituciones", en FACTUM- Revista de Análisis Político, Opinión Pública y Estudios Sociales, 23 de septiembre. http://www.factum.uy/encuestas/2016/enc160923.php.

Bottinelli, Oscar A. (2016b) "Cuando no coinciden la valoración del rumbo y de la gestión del gobierno”, en FACTUM- Revista de Análisis Político, Opinión Pública y Estudios Sociales, 21 de octubre. http://www.factum.uy/analisis/2016/ana161021.php.

Canzani, Agustín (2016) "El drama electoral de 2014. Una mirada crítica desde la opinión pública”, en GARCÉ, Adolfo y Niki JOHNSON (coordinadores) Permanencias, transiciones y rupturas. Elecciones en Uruguay 2014/15. Montevideo: Fin de Siglo.

CEPAL (2015) Panorama Social 2014, disponible en http://repositorio.cepal.org/bitstream/handle/11362/39965/4/S1600175_es.pdf.

Chasquetti, Daniel (2014) Estudio sobre la actividad del Parlamento, $47^{a}$ Legislatura, disponible en http://cienciassociales.edu.uy/wp-content/uploads/2014/09/Chasquetti.pdf. 
Diani, Mario (2015): “Revisando el concepto de movimiento social”, en Encrucijadas. Revista Critica de Ciencias Sociales N9:1-16.

Fabbrini, Sergio (2009) El ascenso del Príncipe democrático. Quién gobierna y cómo se gobiernan las democracias. Buenos Aires: Fondo de Cultura Económica.

Habermas, Jürgen (1996) Between Facts and Norms: Contributions to a Discourse Theory of Law and Democracy. Cambridge, MA: The MIT Press.

LATINOBARÓMETRO (2015) Informe 1995-2015. Santiago de Chile: Corporación Latinobarómetro.

Lissidini, Alicia y Eduardo Blasina (2013) “Uruguay en la nueva agenda posmaterialista: ¿hacia una mayor autonomía y disfrute de la vida?, en http://www.condistintosacentos.com.

Lissidini, Alicia (2014) "Uruguay y la persistente identidad frenteamplista", en Sin Permiso, disponible en http://www.sinpermiso.info/textos/uruguay-y-la-persistenteidentidad-frenteamplista.

Lissidini, Alicia (2016) "Uruguay: derechos y cambio social ¿Un país de izquierda?”, en Revista Nueva Sociedad No 266, noviembre-diciembre, disponible en http://nuso. org/articulo/uruguay-derechos-y-cambio-social/.

Luna, Juan Pablo y Fernando Rosenblatt (2012) “ ¿Notas para una autopsia? Los partidos políticos en el Chile actual”, en http://www.cieplan.org.

Lupu, Noam (2015) "Partisanship in Latin America", en CARLIN, Ryan, Matthew SINGER y Elizabeth ZECHMEISTER (eds.) The Latin American Voter: Pursuing Representation and Accountability in Challenging Contexts. Ann Arbor, MI: University of Michigan Press: 226-245.

Mendiburo-Seguel, Andrés et al (2017) “Attitudes towards drug policies in Latin America: Results from a Latin-American Survey”, en International Journal of Drug Policy 41: 8-13.

Müller Sienra, Christian y Guillermo Draper (2017) Marihuana oficial. Crónica de un experimento uruguayo. Montevideo: Sudamericana.

Orsini, Michal y Miriam Smith (2010) "Social movements, knowledge and public policy: the case of autism activism in Canada and the US", en Critical Policy Studies 4 (1):38-57. 
Pousadela, Inés y Alicia Lissidini (2015) "Hasta la victoria, siembren!", en Revista Anfibia, UNSAM. Disponible en http://www.revistaanfibia.com/ensayo/hasta-la-victoria-siembren/.

Pousadela, Inés (2016) “Social Mobilization and Political Representation:The Women's Movement's Struggle for Legal Abortion in Uruguay”, en Voluntas 27 (1): 125-145.

Pousadela, Inés (2017) "Participation and Representation in Uruguay: Challenges for Social Mobilization in a Party-Centered Society”, en ALBALA, Adrián (comp.) Civil Society and Political Representation in Latin America (2010-2015): Towards a Divorce Between Social Movements and Political Parties? Springer International: 167-192.

Peters, Guy (1996) "Modelos alternativos del proceso de la política pública: de abajo hacia arriba o de arriba hacia abajo”, en Gestión y Política PúblicaVol. 4 N²: 257-276.

Pizzorno, Alessandro (1985) "Sobre la racionalidad de la opción democrática", en Los límites de la democracia, Buenos Aires, CLACSO, 1985:13-52.

Queirolo, Rosario, Lorena Repetto y Cecilia Rossel (2017) “¿Por qué se reguló la marihuana en Uruguay?", presentación en el $9^{\circ}$ Congreso de la Asociación Latinoamericana de Ciencia Política, Montevideo, 28 de julio.

Rosanvallon, Pierre (2017) "La democracia del siglo XXI”, en Revista Nueva Sociedad Mayo-Junio. http://nuso.org/articulo/la-democracia-del-siglo-xxi/.

Tilly, Charles y Sidney Tarrow (2015) Contentious Politics. NuevaYork: Oxford University Press.

\section{Fuentes periodísticas en línea}

Agencia EFE (EFE, http:///www.efe.com), BBC (http://www.bbc.com), Brecha (http:// www.brecha.com.uy), Búsqueda (http://www.busqueda.com.uy), Caras y Caretas CNN en español (CNN, http://cnnespanol.cnn.com), El Espectador (EE, http://www.espectador.com), El Observador (EO, http://www.elobservador.com.uy), El País (EP, http:// www.elpais.com.uy/), El País (España) (EP-España, http://www.elpais.com), Folha de São Paulo (FSP, http://www1.folha.uol.com.br), Infobae (IB, http://www.infobae.com), IPS Noticias (IPS, http://ipsnoticias.net), La Diaria (LD, http://ladiaria.com.uy/), La Red 21, (LR21, http://www.lr21.com.uy), La República (LR, http://www.diariolarepublica.net), Montevideo Portal (MP, http://www.montevideo.com.uy), Portal 180 (P180, http://www.180.com.uy), Subrayado (http://www.subrayado.com.uy), Teledoce (T12, http://www.teledoce.com), Telesur TV (TS, http://www.telesurtv.net). 


\section{Entrevistas}

Milton Romani, ex Secretario General de la Junta Nacional de Drogas, 11/12/16

Julio Calzada, ex Secretario General de la Junta Nacional de Drogas, 11/12/16

Eduardo Blasina, director del Museo del Cannabis y de una de las empresas seleccionadas para cultivar marihuana $(8 / 12 / 16$ y $10 / 11 / 17)$

Conversaciones informales con activistas y expertos en ExpoCannabis 2015 (5 al 7/12, LATU Montevideo) y ExpoCannabis 2016 (10 al 12/12, LATU Montevideo)

\section{Cómo citar este artículo}

Lissidini, Alicia e Inés Pousadela (2018) “El experimento uruguayo: Actores políticos y sociales en el proceso de regulación del cannabis". Revista Perspectivas de Políticas Públicas vol. 7 No14: 367-392 